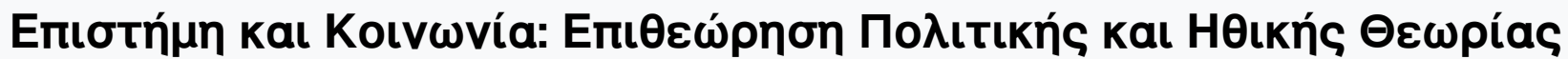

Tó 19 (2008)

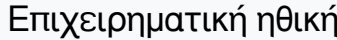

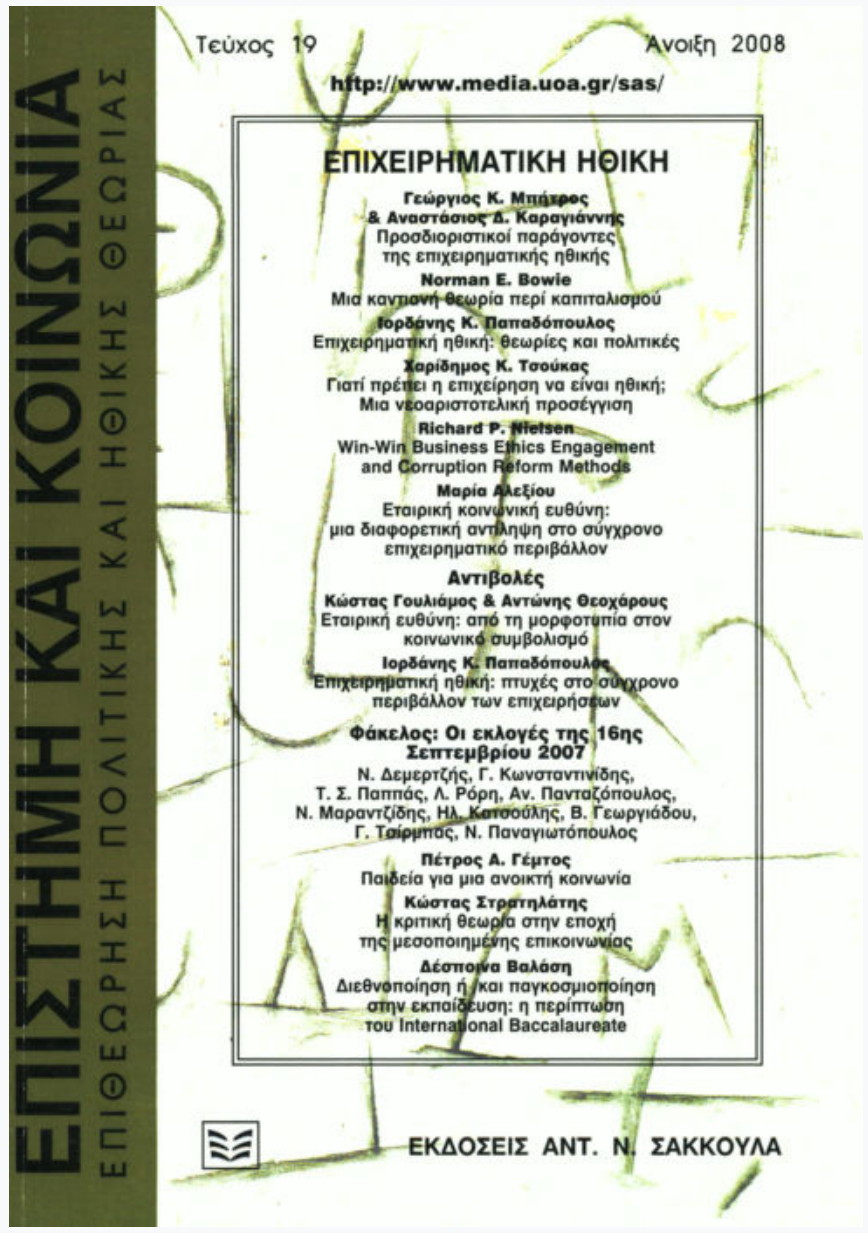

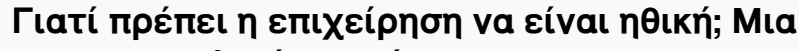

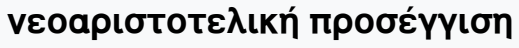

Харі́бпнос K. Тбои́каৎ

doi: $10.12681 /$ sas. 657

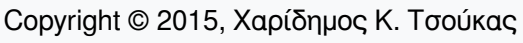

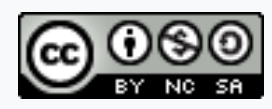

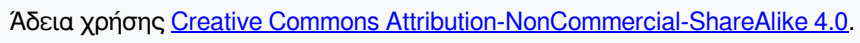

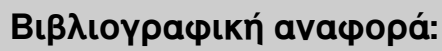

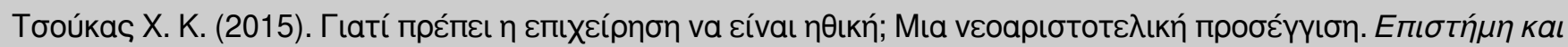

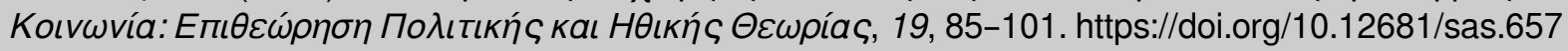




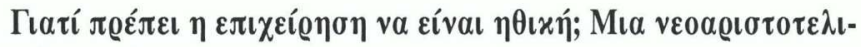

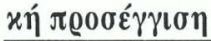

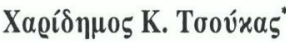

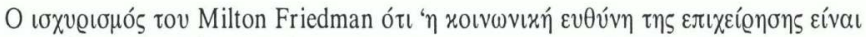

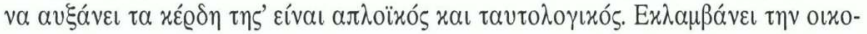

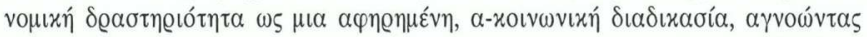

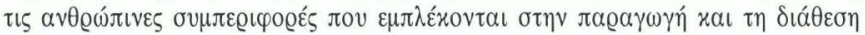

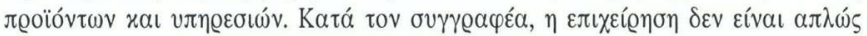

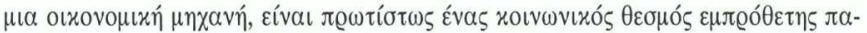

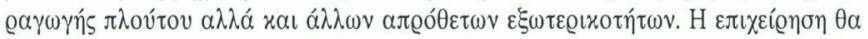

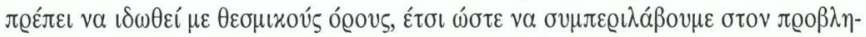

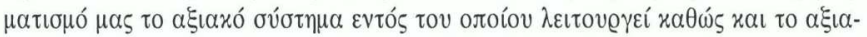

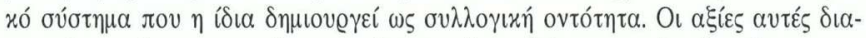

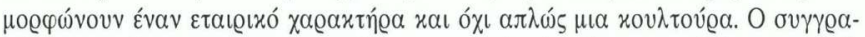

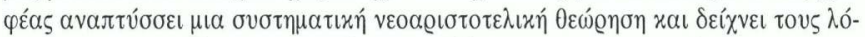

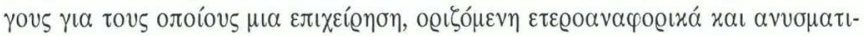

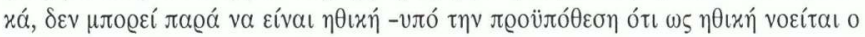

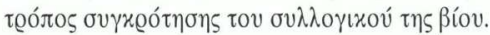

\section{The business of business is business}

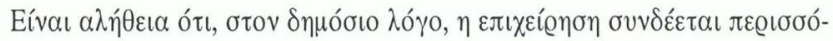

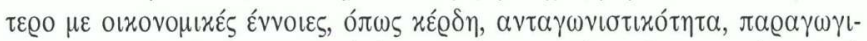

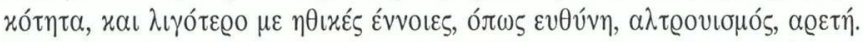

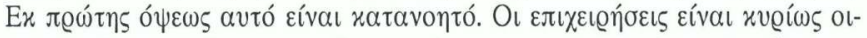

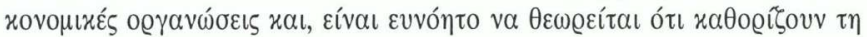

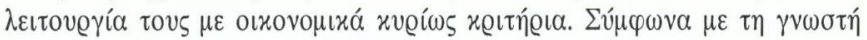

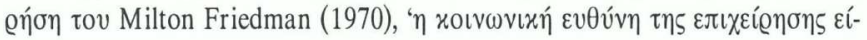

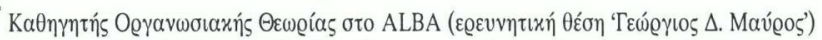

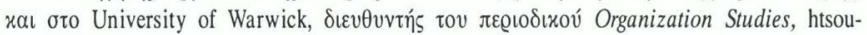
kas@alba.edu.gr. 


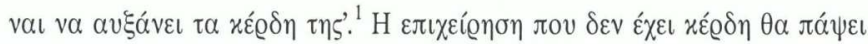

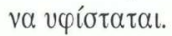

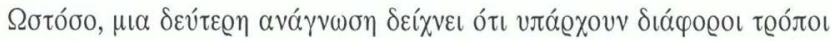

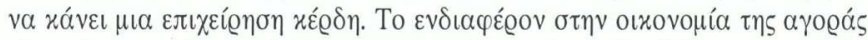

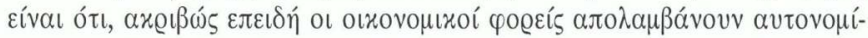
$\alpha \zeta, \mu \pi$

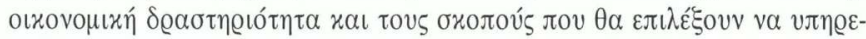

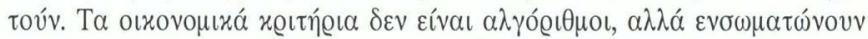

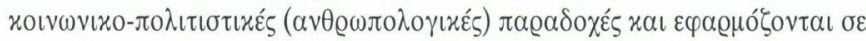

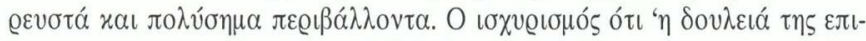

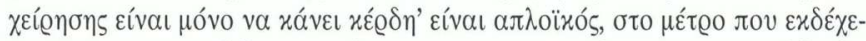

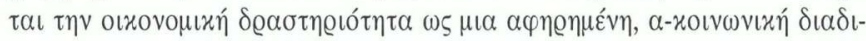

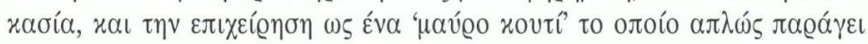

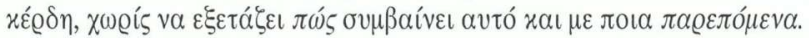

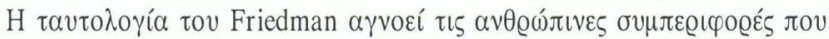

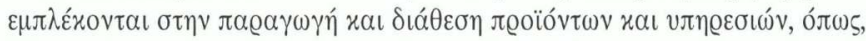

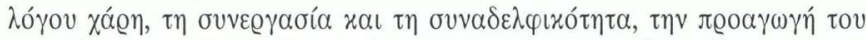

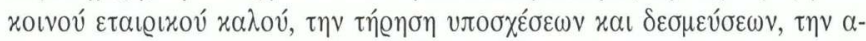

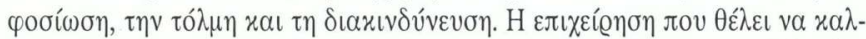

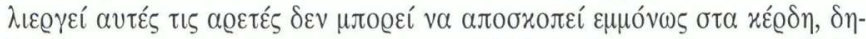

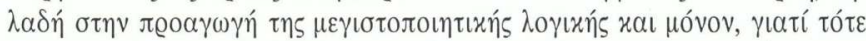

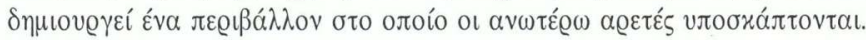

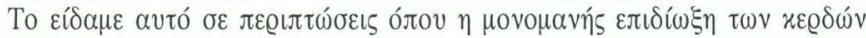

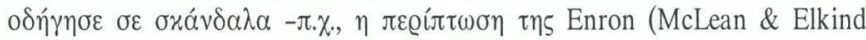

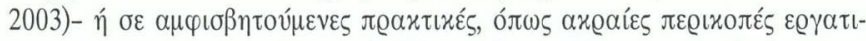

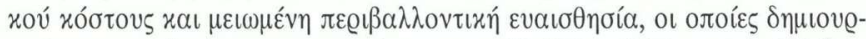

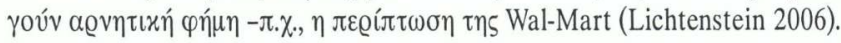

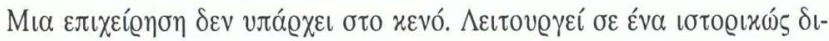

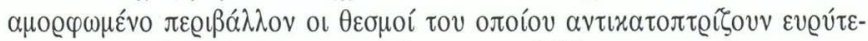

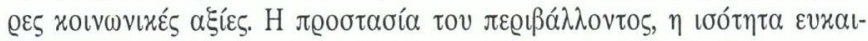

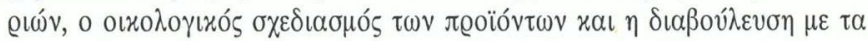

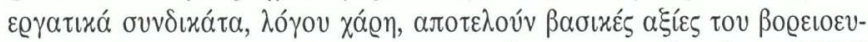

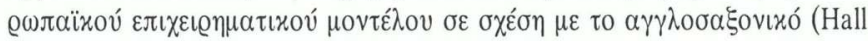

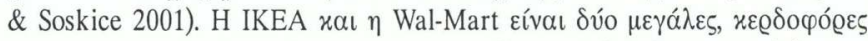

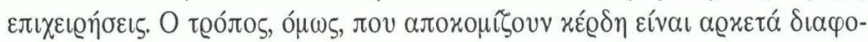




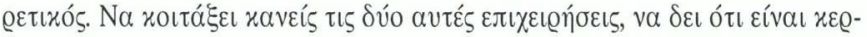

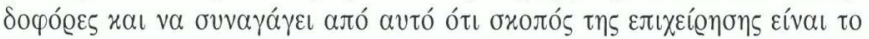

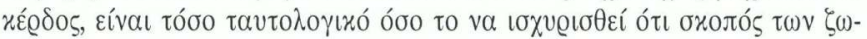

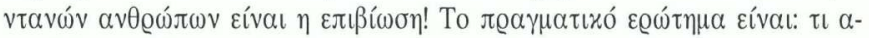

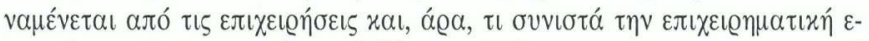

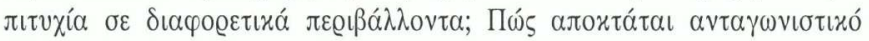

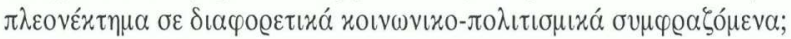

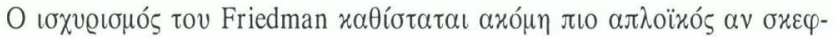

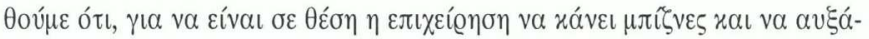

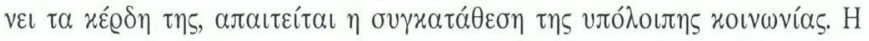

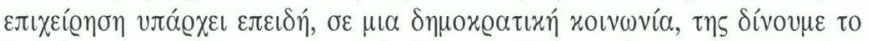

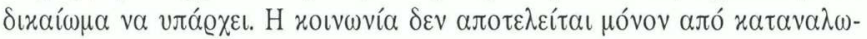

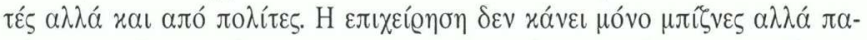

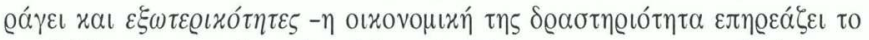

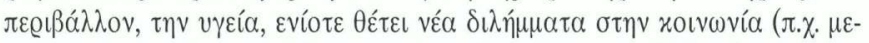

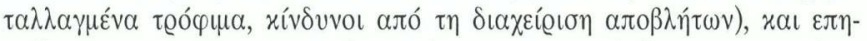

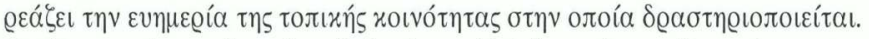

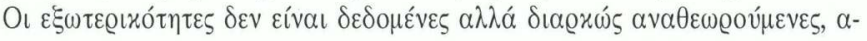

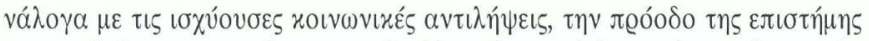

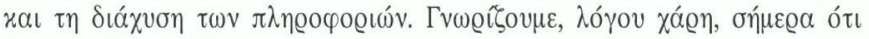

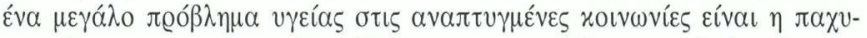

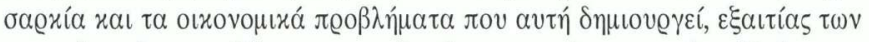

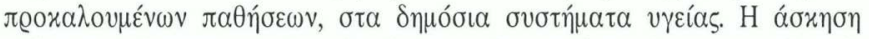

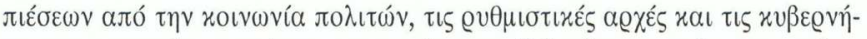

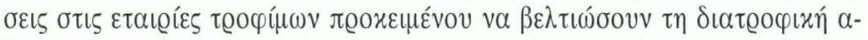

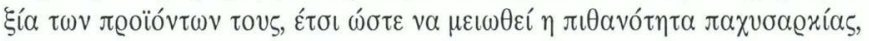

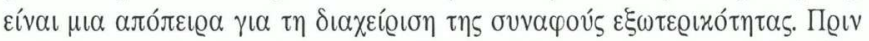

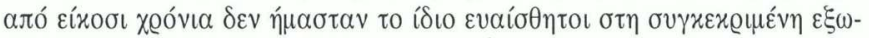

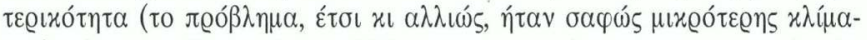

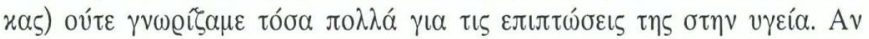

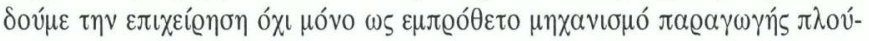

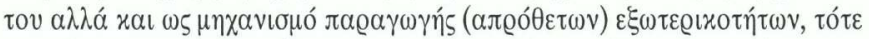

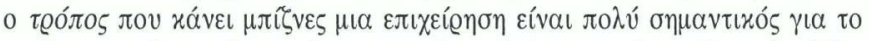

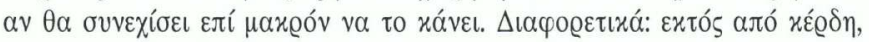

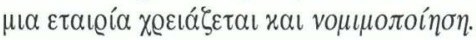




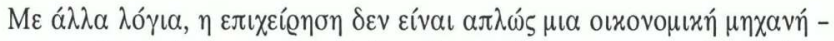

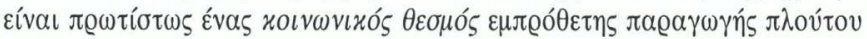

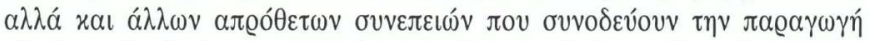

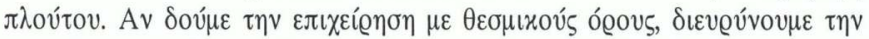

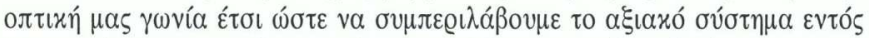

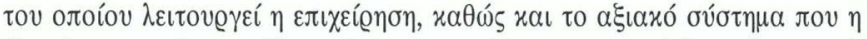

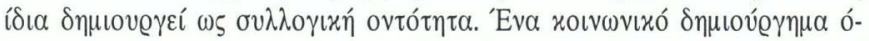

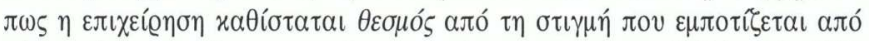

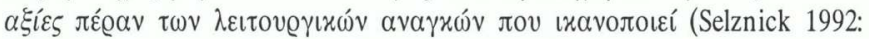

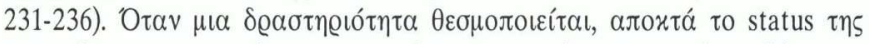

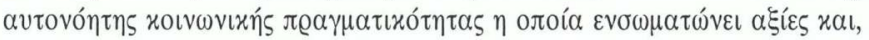

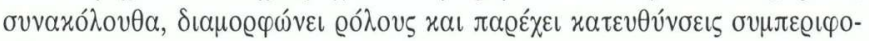
@ás.

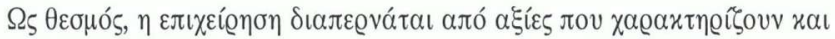

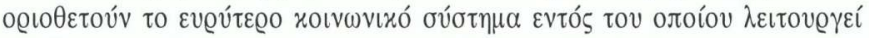

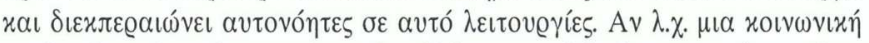

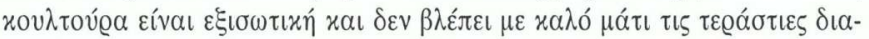

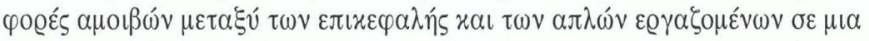

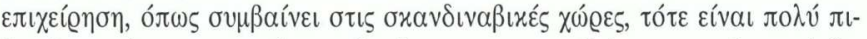

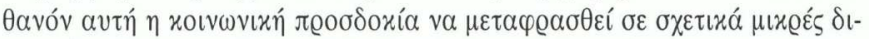

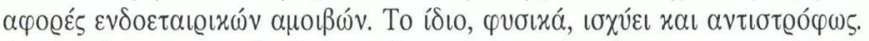

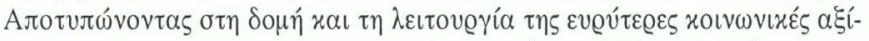

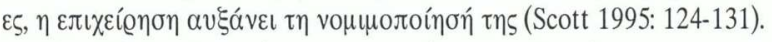

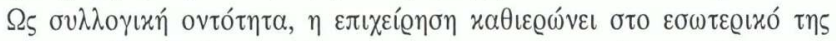

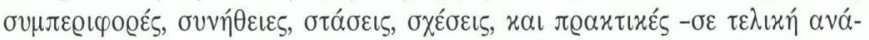

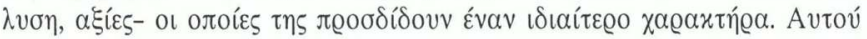

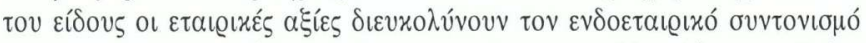

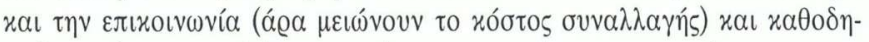

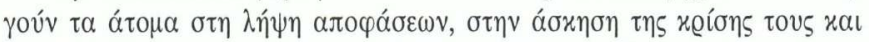

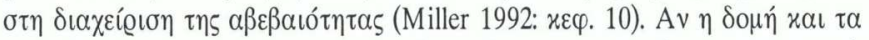

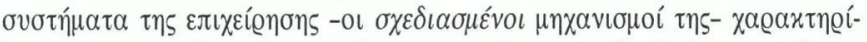

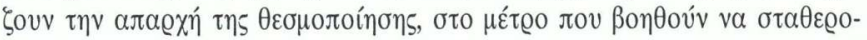

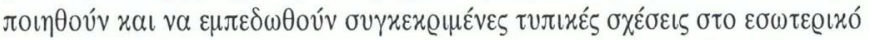

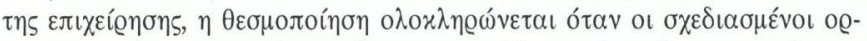

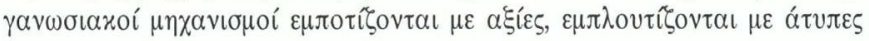




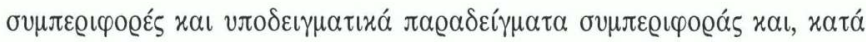

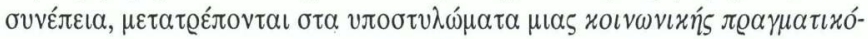

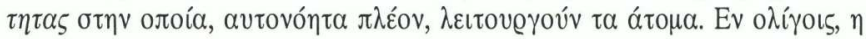

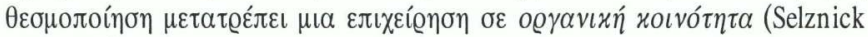
1992: 235).

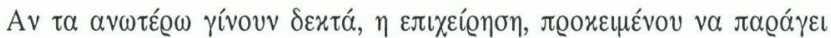

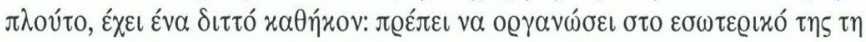

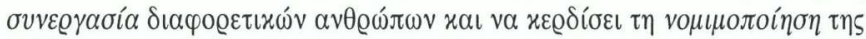

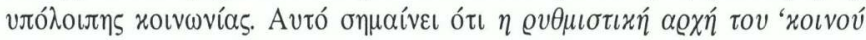

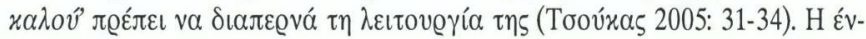

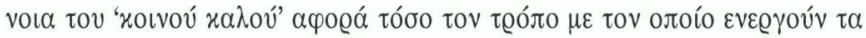

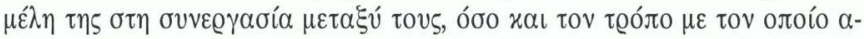

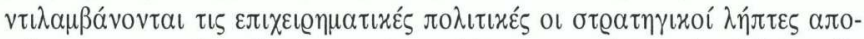

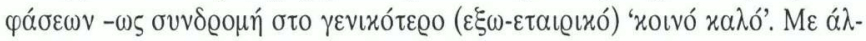

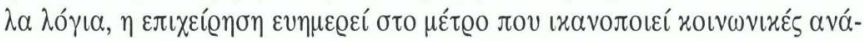

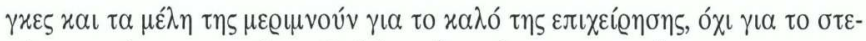

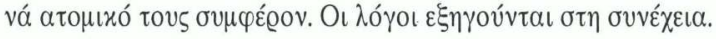

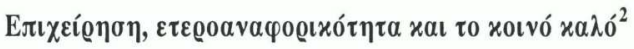

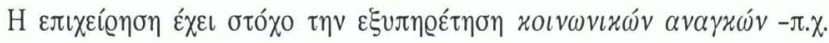

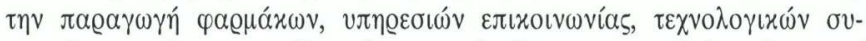

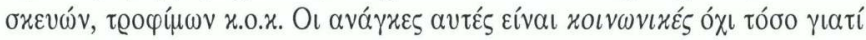

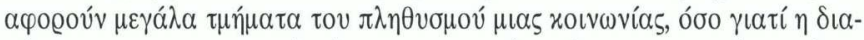

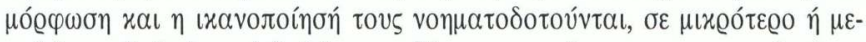

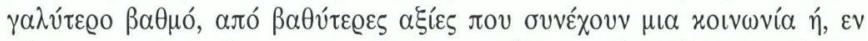

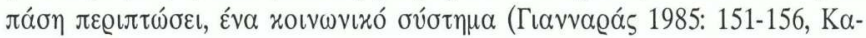

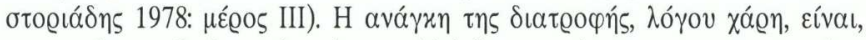

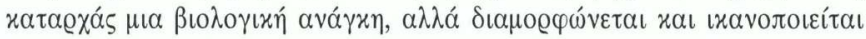

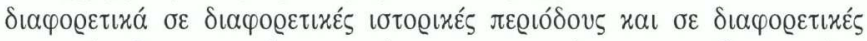

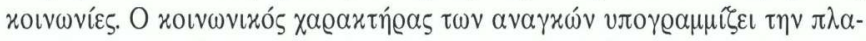

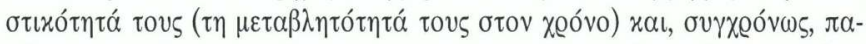

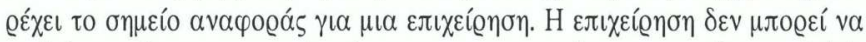

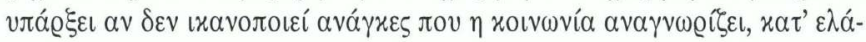

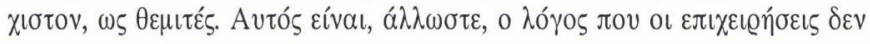




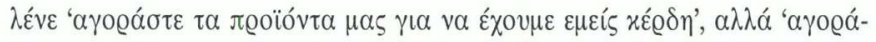

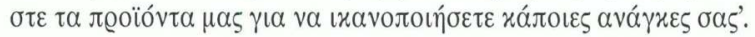

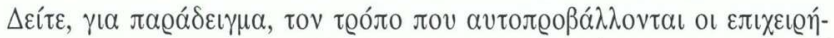

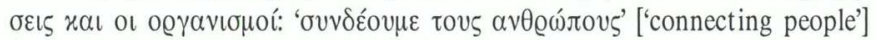

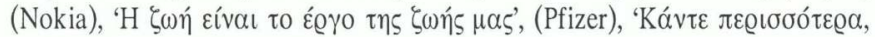

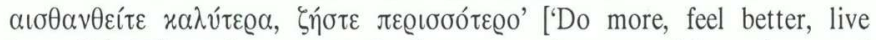

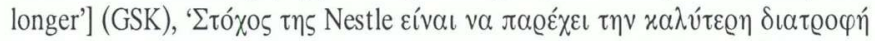

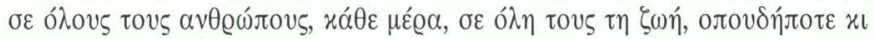

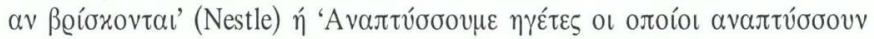

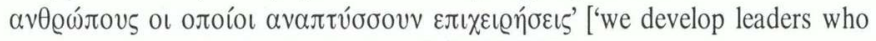
develop people who develop business'] (INSEAD).

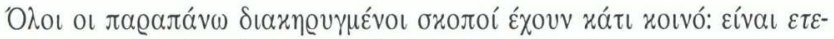

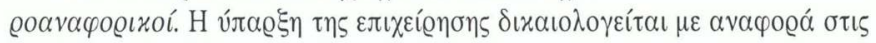

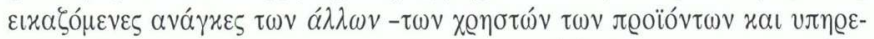

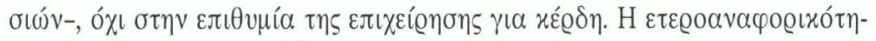

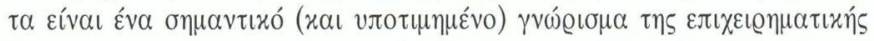

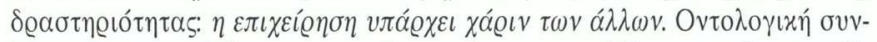

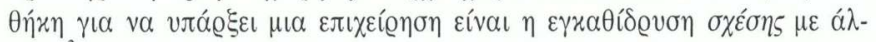
hovs. ${ }^{3}$

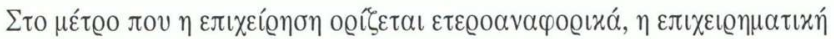

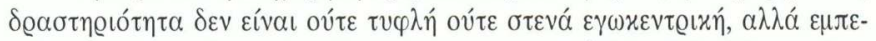

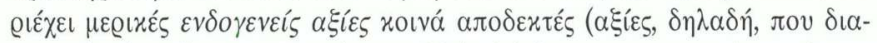

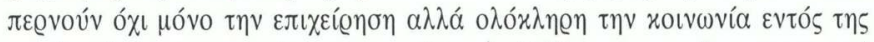

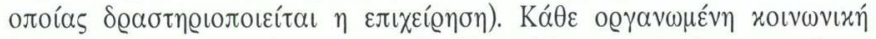

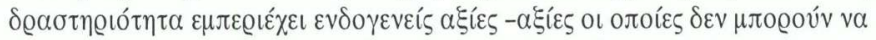

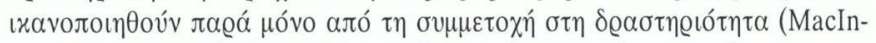

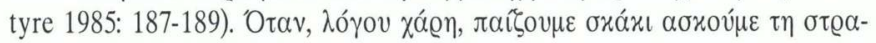

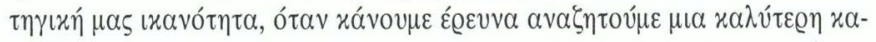

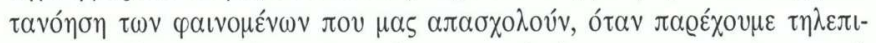

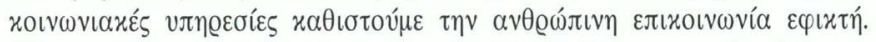

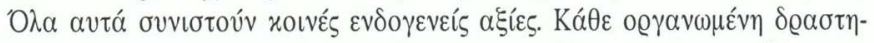

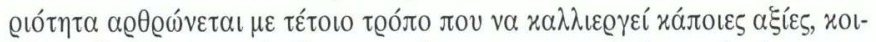

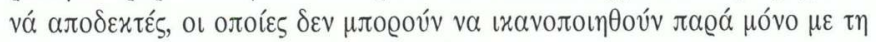

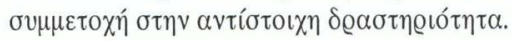




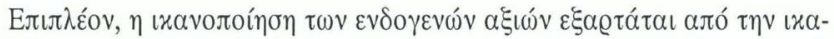

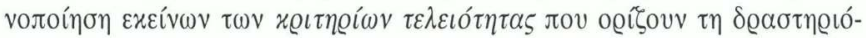

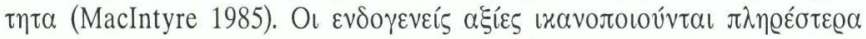

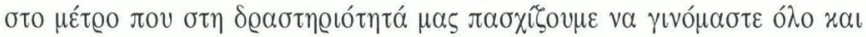

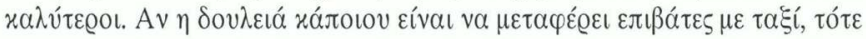

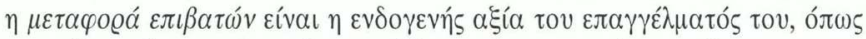

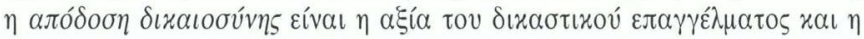

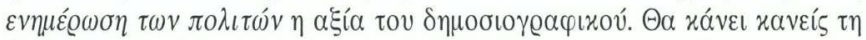

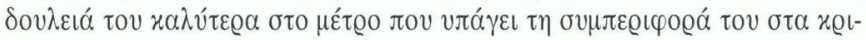

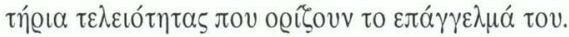

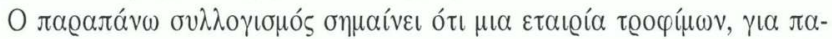

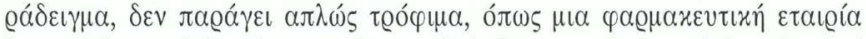

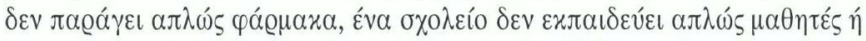

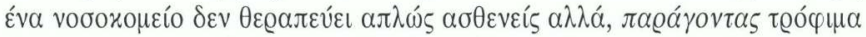

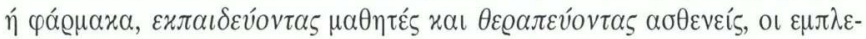

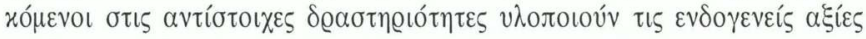

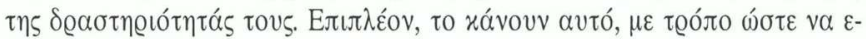

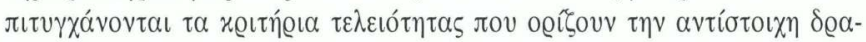

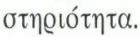

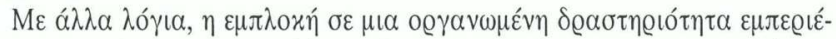

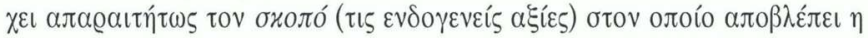

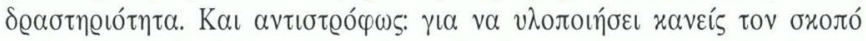

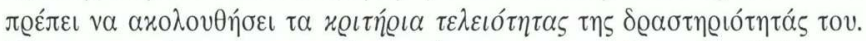

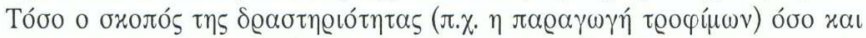

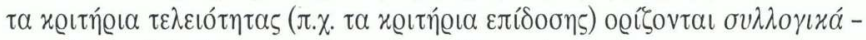

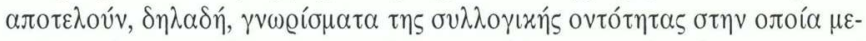

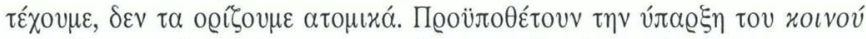

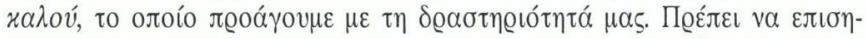

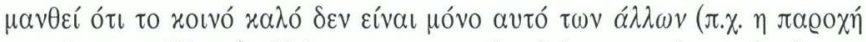

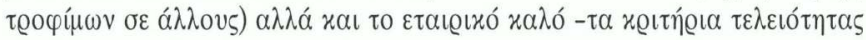

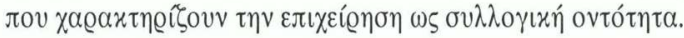

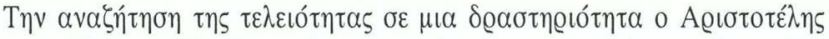

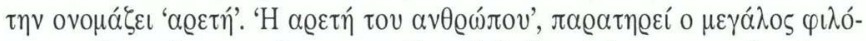

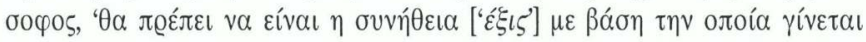

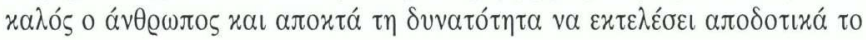




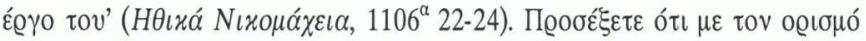

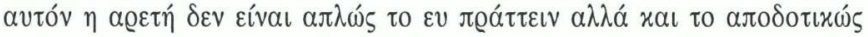

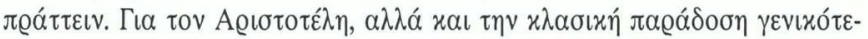

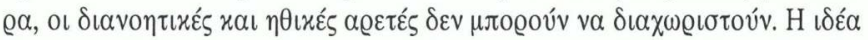

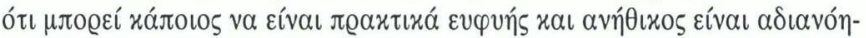

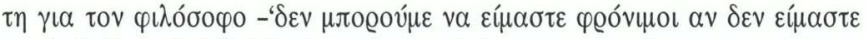

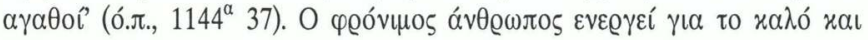

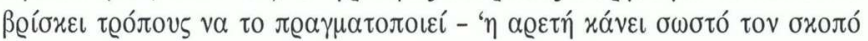

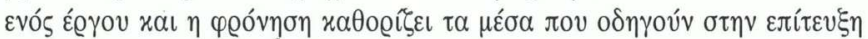

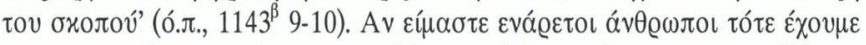

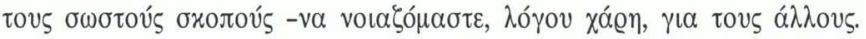

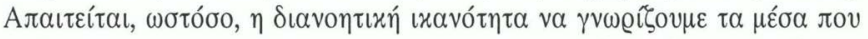

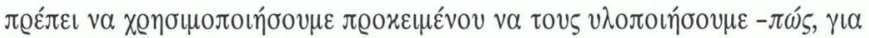

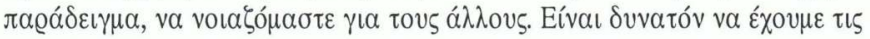

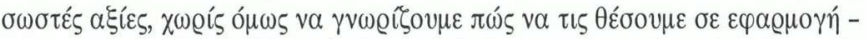

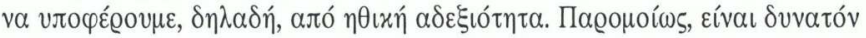

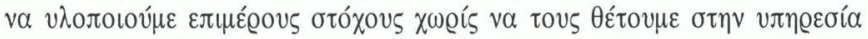

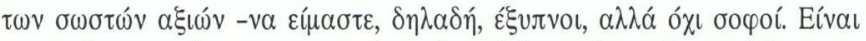

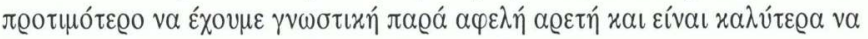

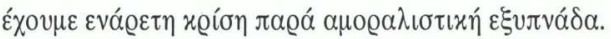

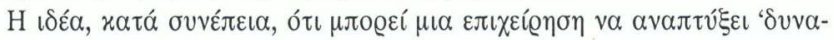

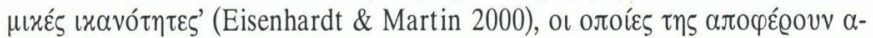

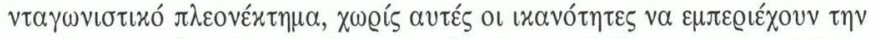

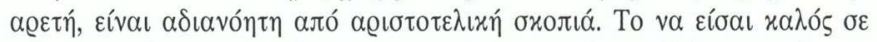

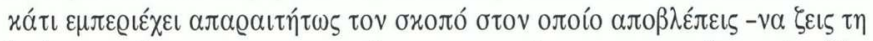

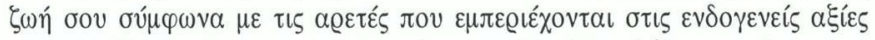

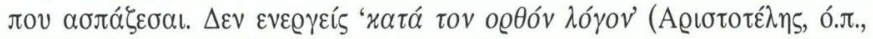

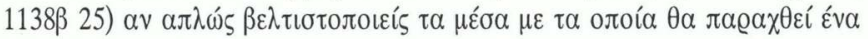

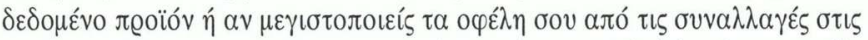

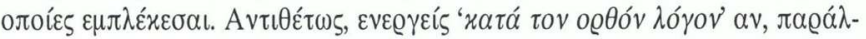

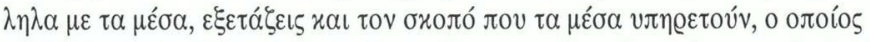

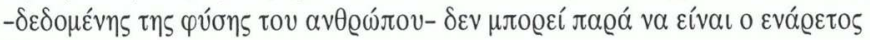
Bíos.

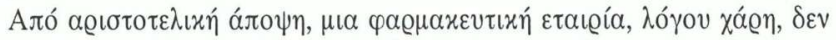

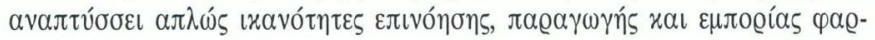




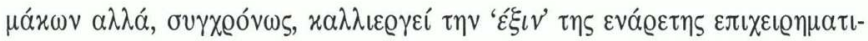

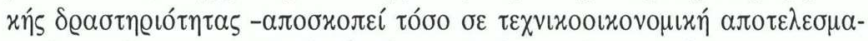

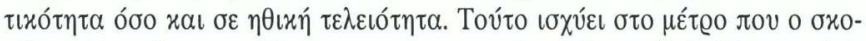

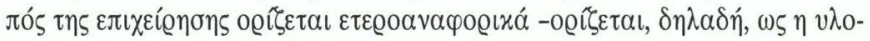

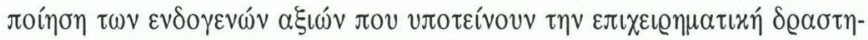

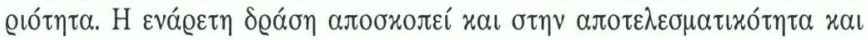

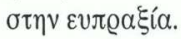

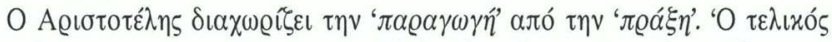

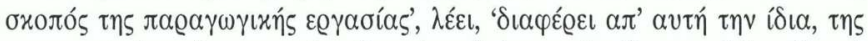

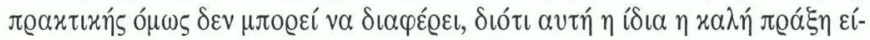

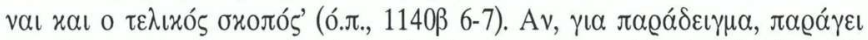

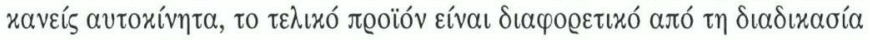

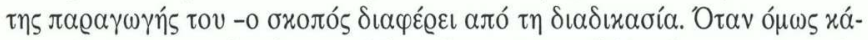

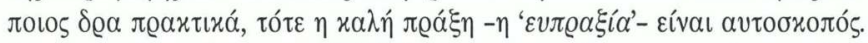

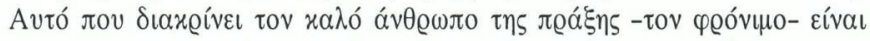

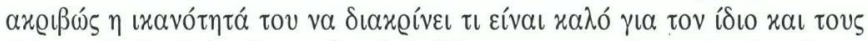

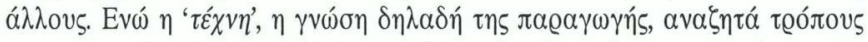

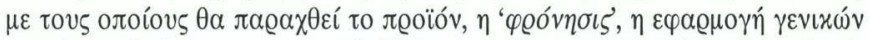

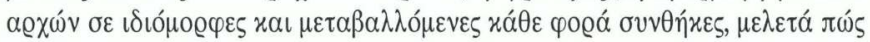

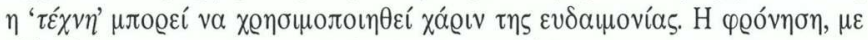

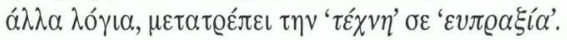

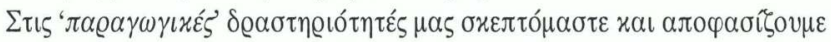

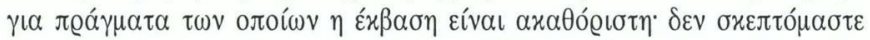

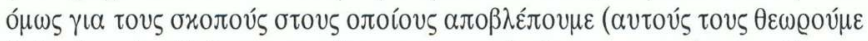

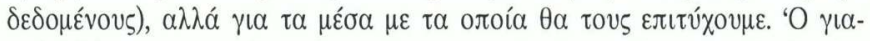

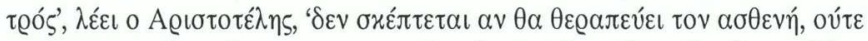

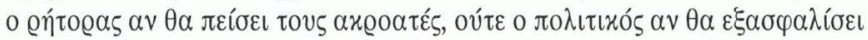

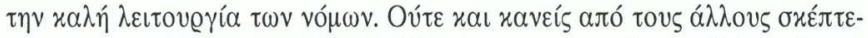

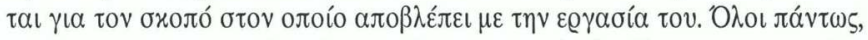

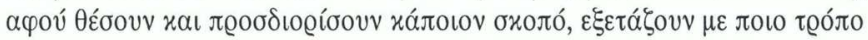

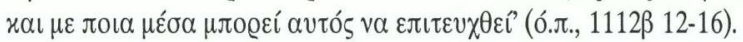

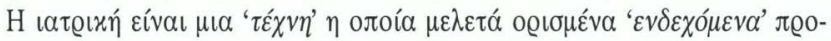

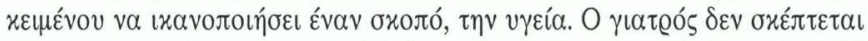

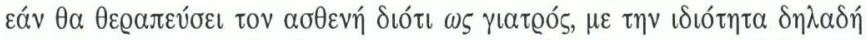

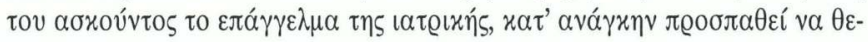




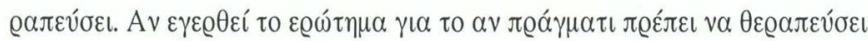

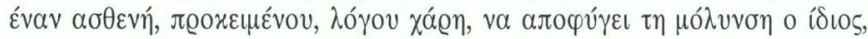

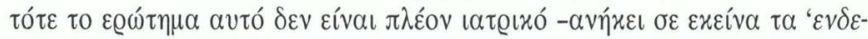

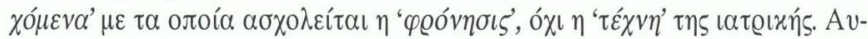

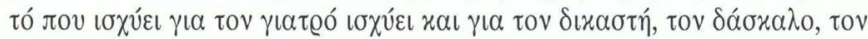

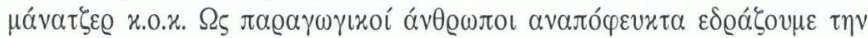

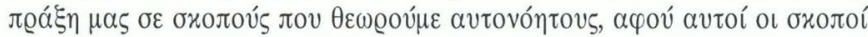

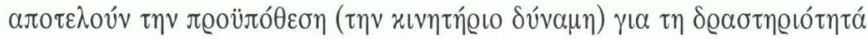

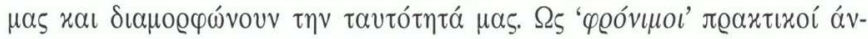

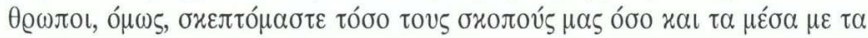

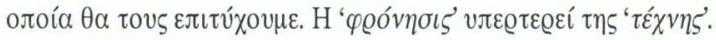

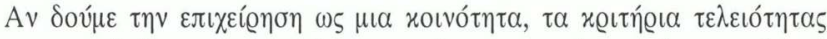

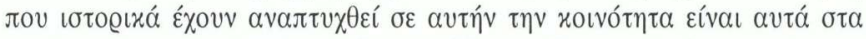

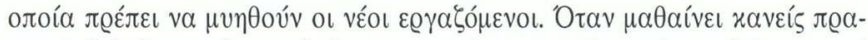

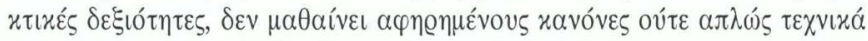

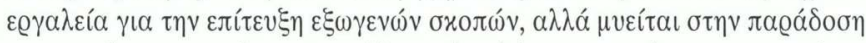

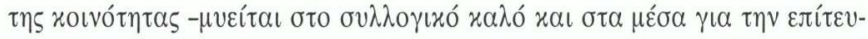

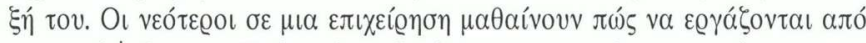

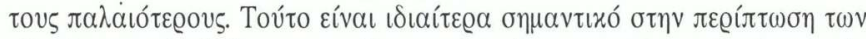

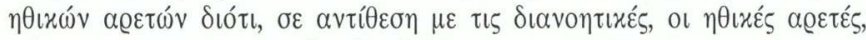

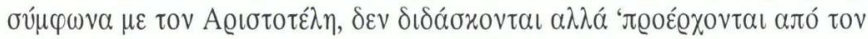

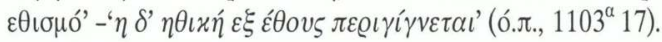

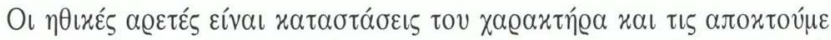

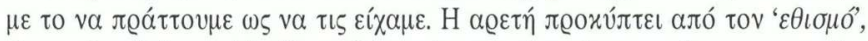

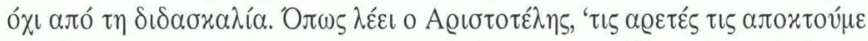

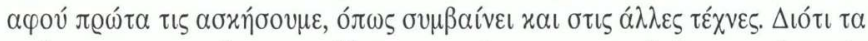

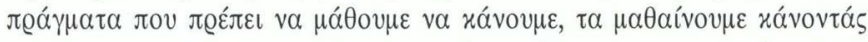

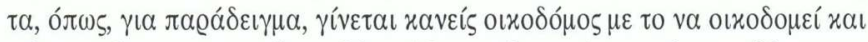

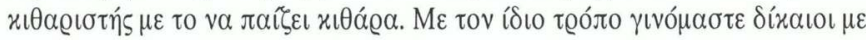

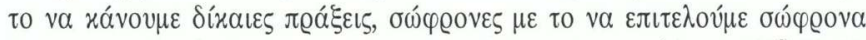

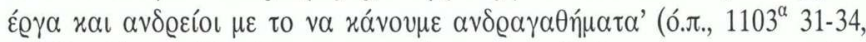

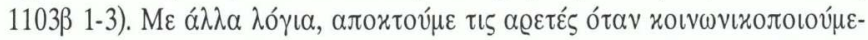

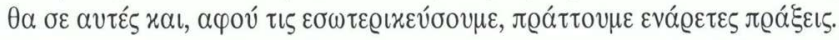

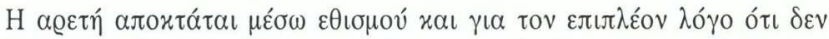

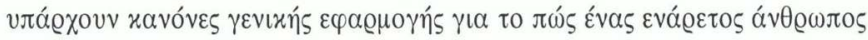




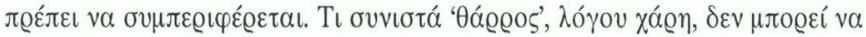

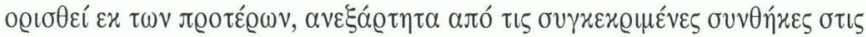

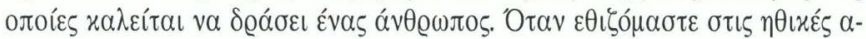

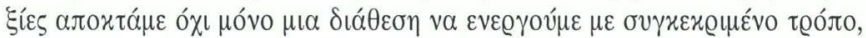

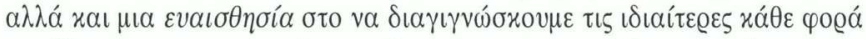

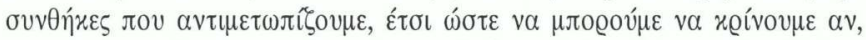

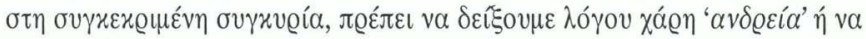

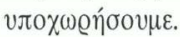

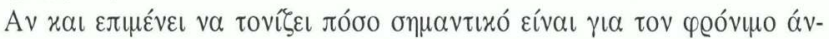

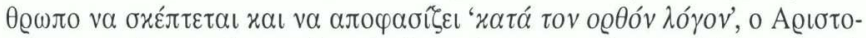

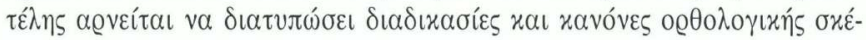

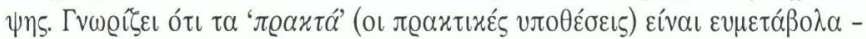

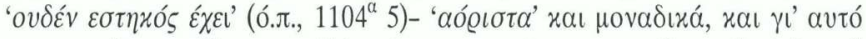

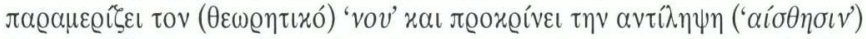

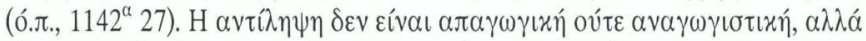

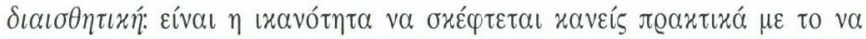

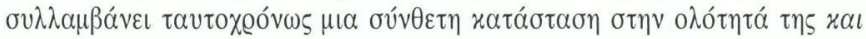

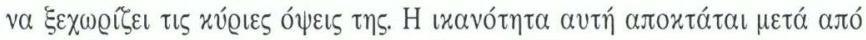

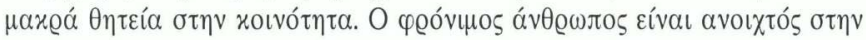

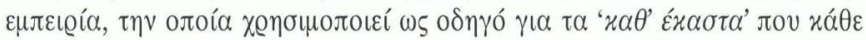

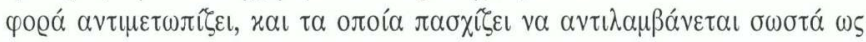
Éxouv.

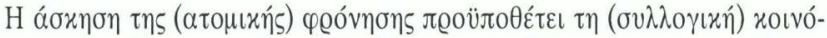

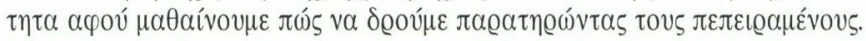

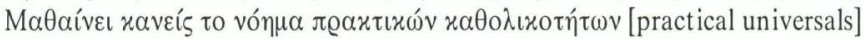

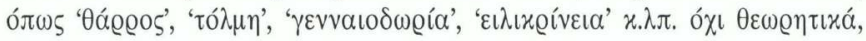

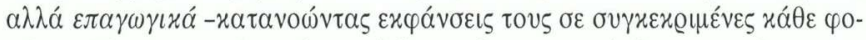

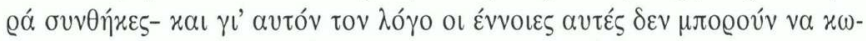

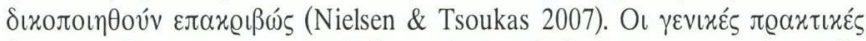

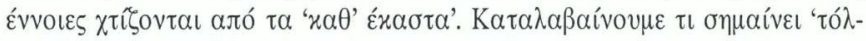

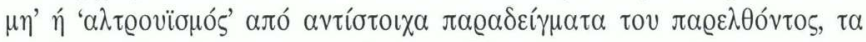

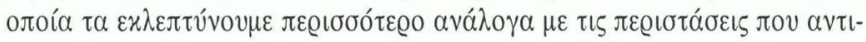

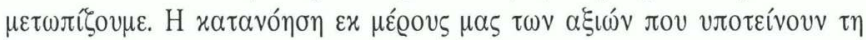

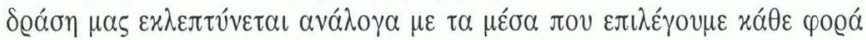

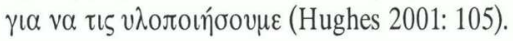




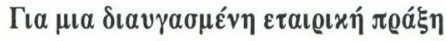

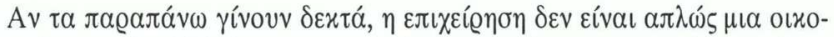

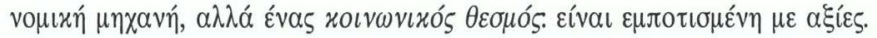

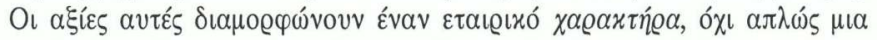

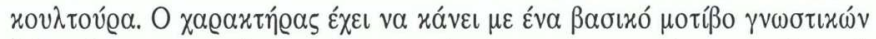

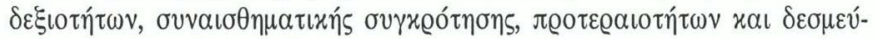

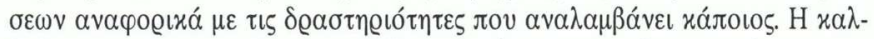

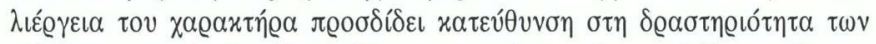

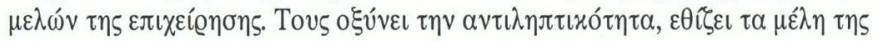

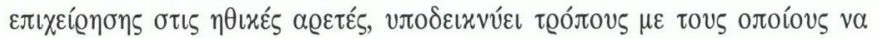

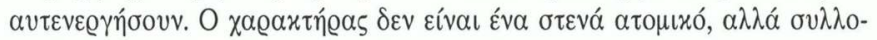

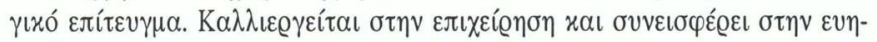

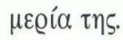

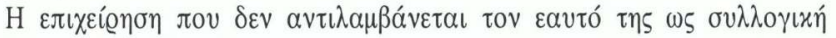

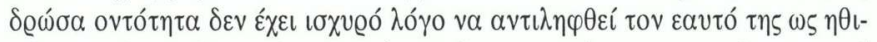

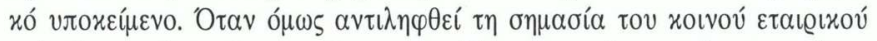

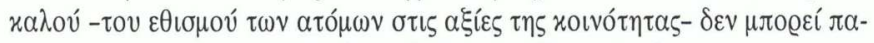

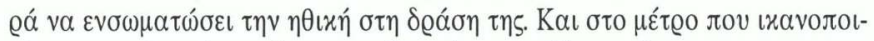

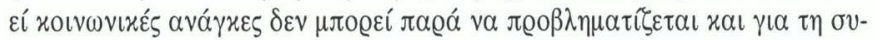

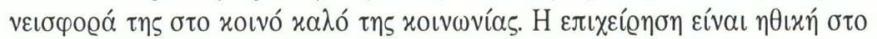

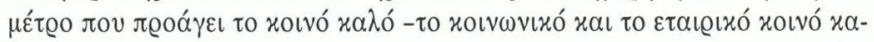

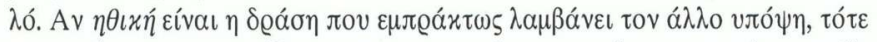

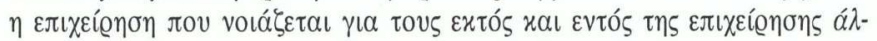

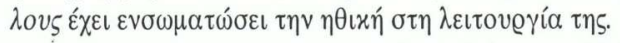

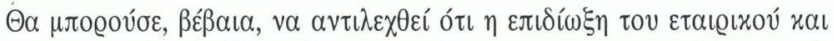

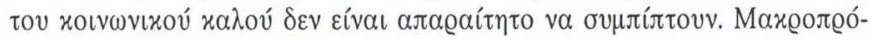

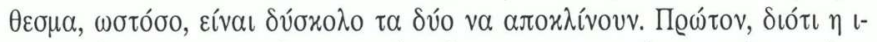

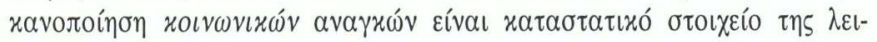

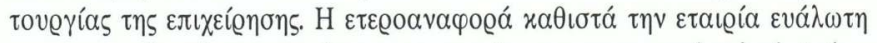

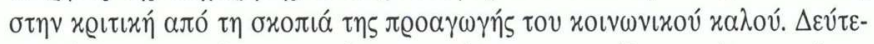

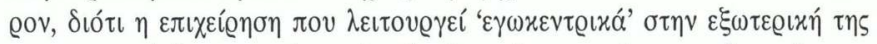

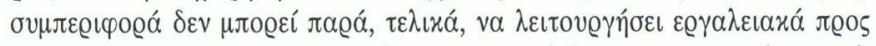

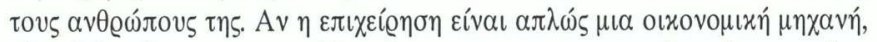

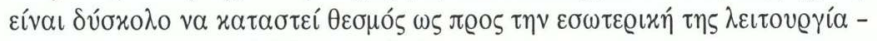

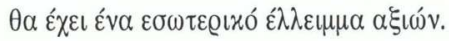




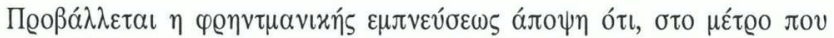

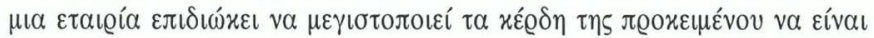

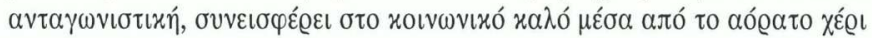

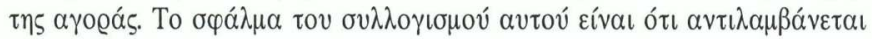

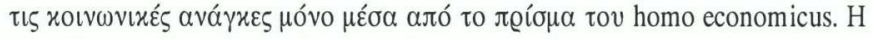

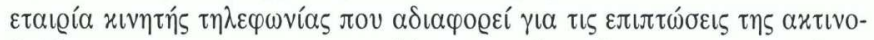

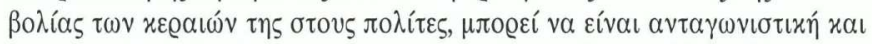

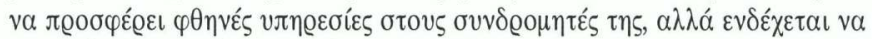

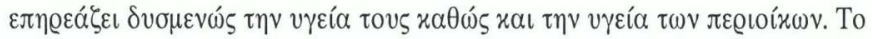

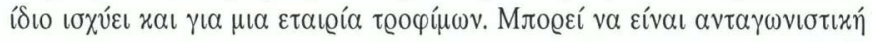

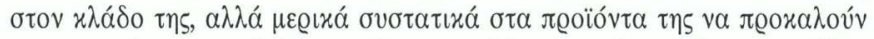

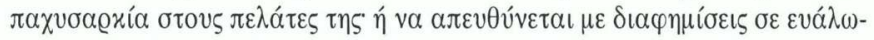

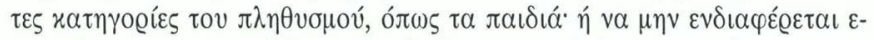

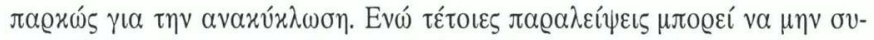

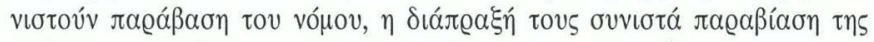

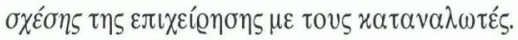

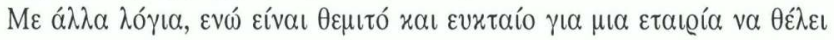

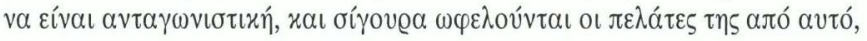

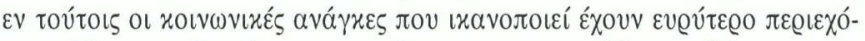

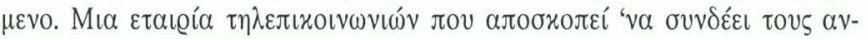

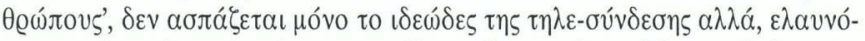

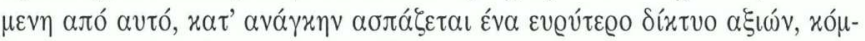

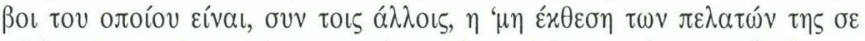

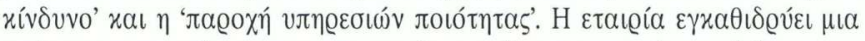

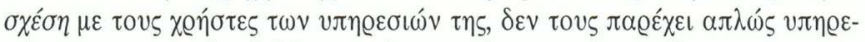

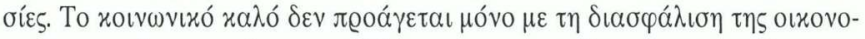

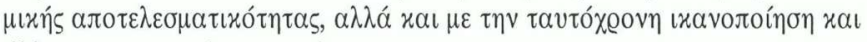

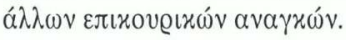

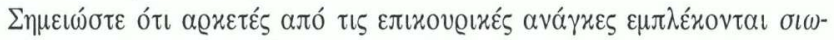

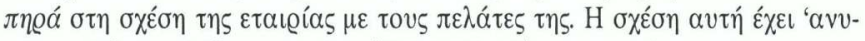

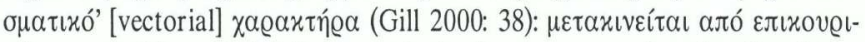

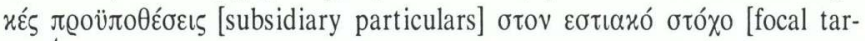

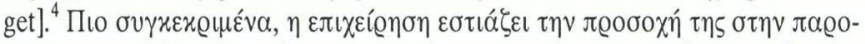

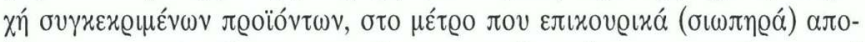

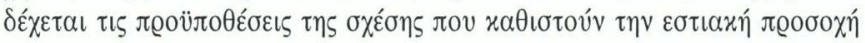




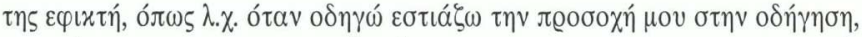

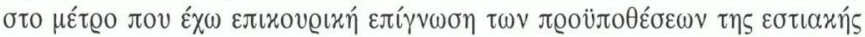

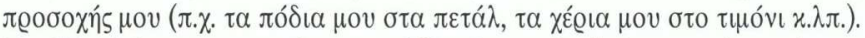

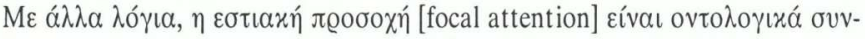

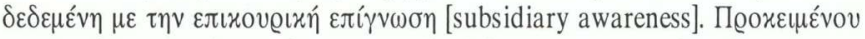

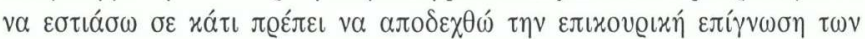

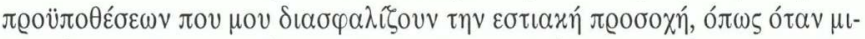

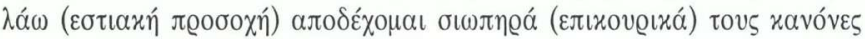

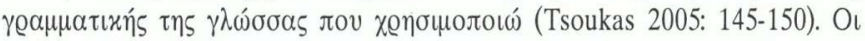

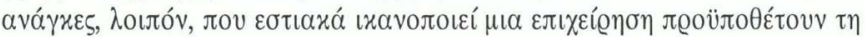

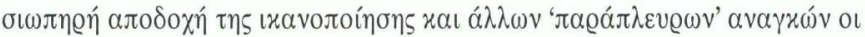

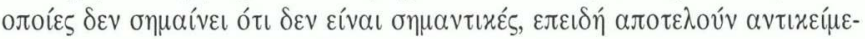

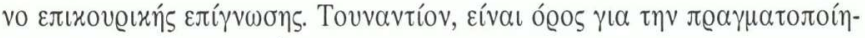

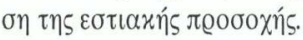

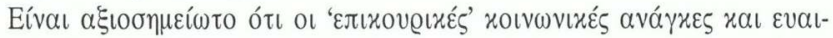

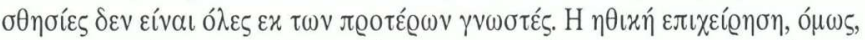

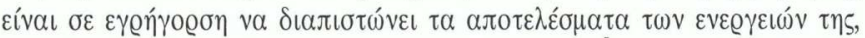

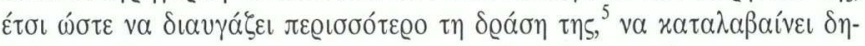

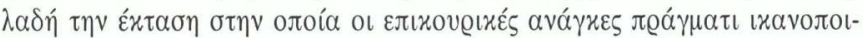

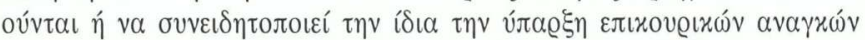

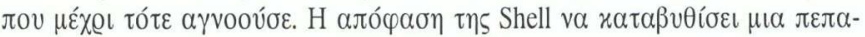

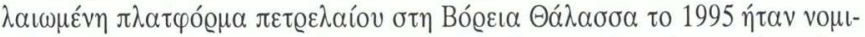

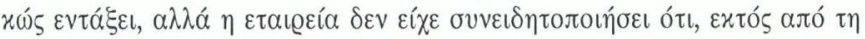

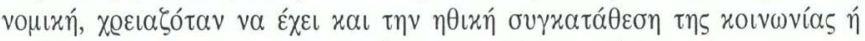

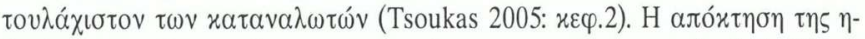

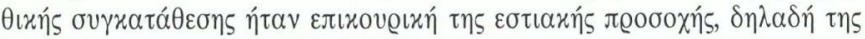

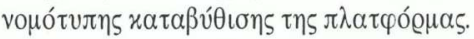

\section{$\Sigma v \mu \pi \varepsilon \varrho \alpha ́ \sigma \mu \alpha \tau \alpha$}

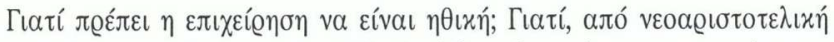

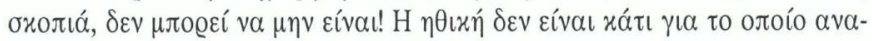

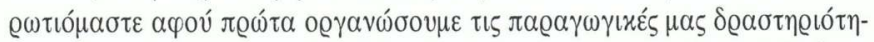

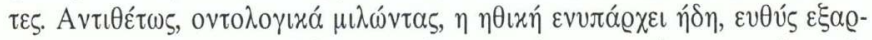

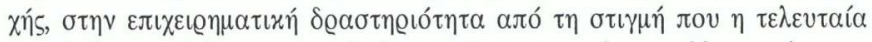

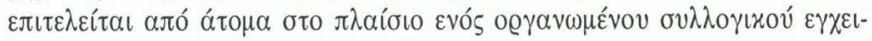




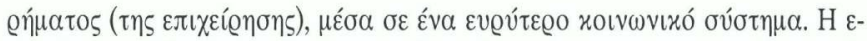

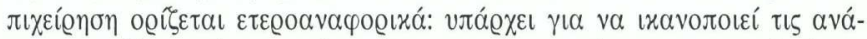

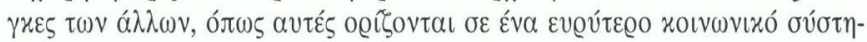

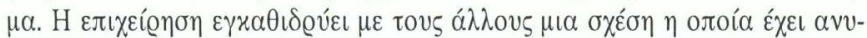

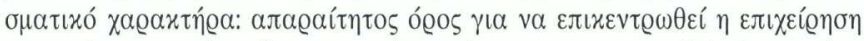

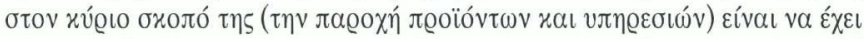

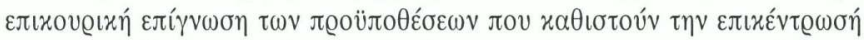

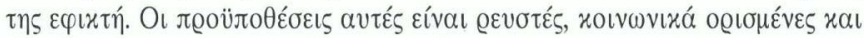

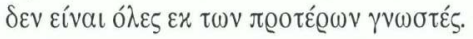

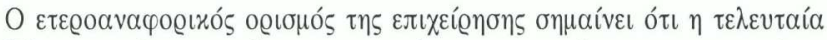

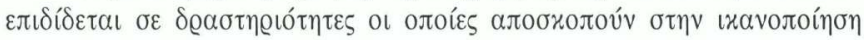

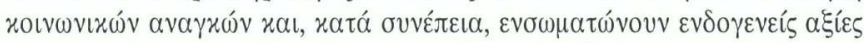

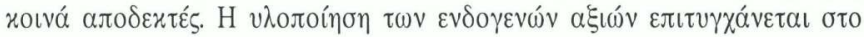

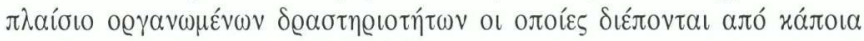

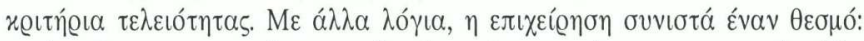

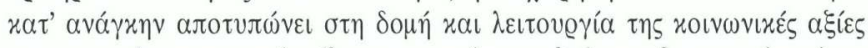

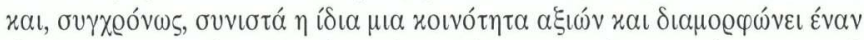

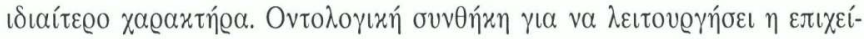

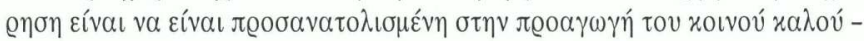

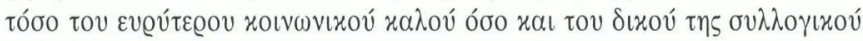
xàov́.

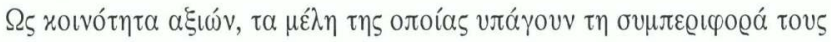

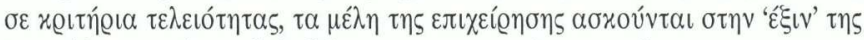

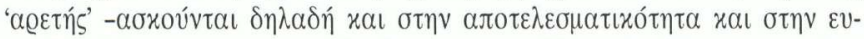

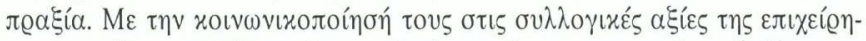

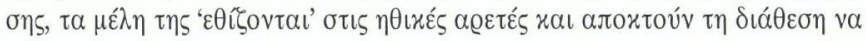

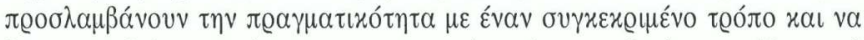

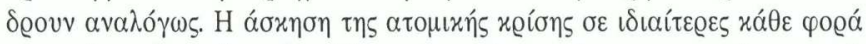

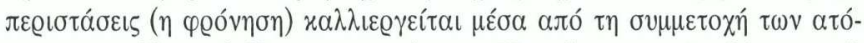

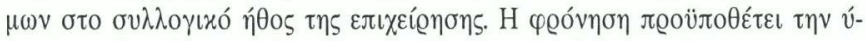

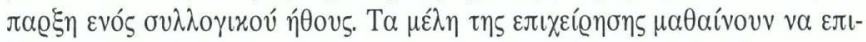

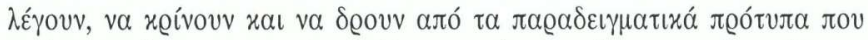

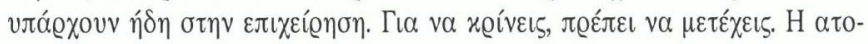

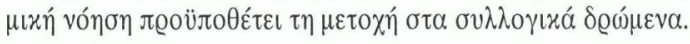




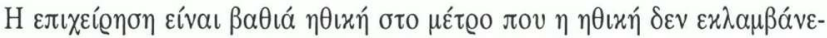

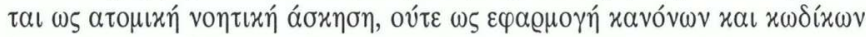

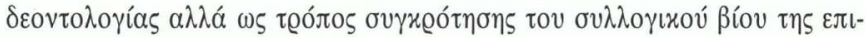

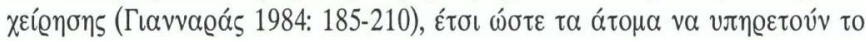

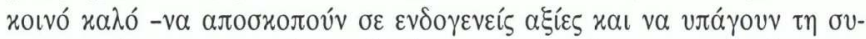

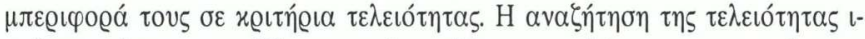

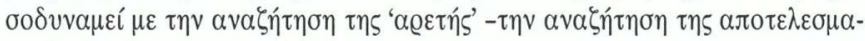

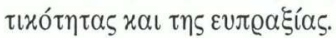

\section{$\Sigma \eta \mu \varepsilon เ \omega ́ \sigma \varepsilon เ \zeta$}

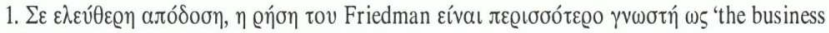
of business is business'.

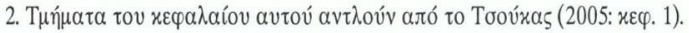

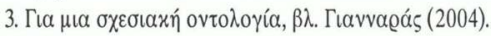

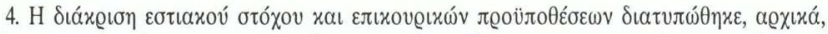

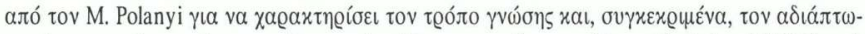

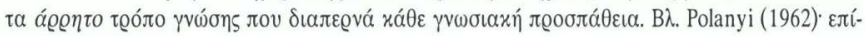
ons, Tsoukas (2005: $к \varepsilon \varphi .6)$. 154).

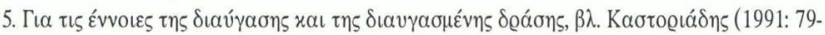

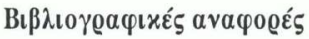

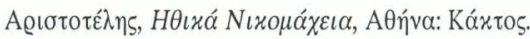

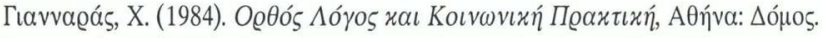

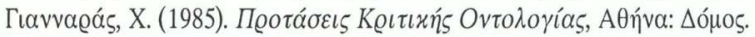

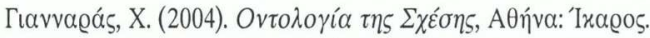

Eisenhardt, K. \& Martin, J.A. (2000). 'Dynamic capabilities: The evolution of resources in dynamic markets', Strategic Management Journal, 21:1105-1121.

Friedman, M. (1970). 'The social responsibility of business is to increase its profits',

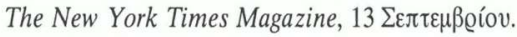

Gill, J.H. (2000). The Tacit Mode: Michael Polanyi's Postmodern Philosophy, New York: State University of New York Press. 
Hall, P.A. \& Soskice, D. (2001). Varieties of Capitalism: The Institutional Foundations of Comparative Advantage, Oxford: Oxford University Press.

Hughes, G.J. (2001). Aristotle on Ethics, London: Routledge.

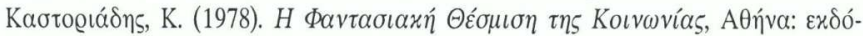

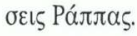

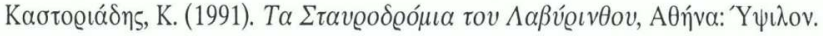

Lichtenstein, N. (2006). Wal-Mart: The Face of Twenty-First-Century Capitalism, New York: New Press.

MacIntyre, A. (1985). After Virtue, London: Duckworth.

McLean, B. \& Elkind, P. (2003). Smartest Guys in the Room: The Amazing Rise and Scandalous Fall of Enron, New York: Penguin.

Miller, G.J. (1992). Managerial Dilemmas: The Political Economy of Hierarchy, Cambridge: Cambridge University Press.

Nielsen, R. \& Tsoukas, H. (2007). 'Towards an Aristotelian reading of Argyris' con-

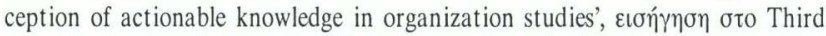
Organization Studies Summer Workshop on 'Organization Studies as Applied Science: The Generation and Use of Academic Knowledge about Organizations',

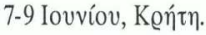

Polanyi, M. (1962). Personal Knowledge: Towards a Post-Critical Philosophy, Chicago: The University of Chicago Press.

Scott, R. (1995). Institutions and Organizations, Thousand Oaks, CA: Sage.

Selznick, P. (1992). The Moral Commonwealth: Social Theory and the Promise of Community, Berkeley, CA: University of California Press.

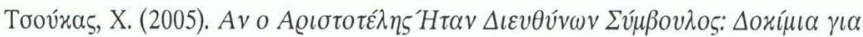

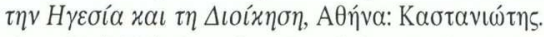

Tsoukas, H. (2005) Complex Knowledge: Studies in Organizational Epistemology, Oxford: Oxford University Press. 